\title{
Implementasi Undang-Undang Nomor 15 Tahun 2016 dalam Melindungi Hak-Hak Anak Buah Kapal di PT Samudera Indonesia
}

\author{
Fakhrurrozi ${ }^{1}$, Ridwan $^{2}$ \\ ${ }^{1,2}$ Politeknik Bumi Akpelni, Semarang \\ ${ }^{1}$ fakhrurrozi@akpelni.ac.id, ${ }^{2}$ ridwan@akpelni.ac.id
}

Diterima 18 Desember 2020, direvisi 21 Januari 2021, diterbitkan 08 Maret 2021

\begin{abstract}
Abstrak
Anak Buah Kapal (ABK) adalah semua orang yang bekerja di kapal, yang bertugas untuk mengoperasikan dan memelihara kapal dan muatannya, selain Nahkoda atau pemimpin kapal. Dalam menjalankan tugasnya mereka sering mengalami kesulitan mulai dari penipuan lowongan pekerjaan, kekerasan, penggajian yang masih dibawah upah minimum, hingga kejahatan perampokan dan penganiayaan. Penelitian ini bertujuan untuk membahas mengenai Implementasi Undang-Undang No 15. Tahun 2016 dalam melindungi hak-hak Anak Buah Kapal, dalam studi kasus penelitian di PT Samudera Indonesia, cabang Semarang. Penelitian ini didasarkan pada penelitian yuridis empiris yang berbasis pada ilmu hukum normatif atau peraturan perundang-undangan. Sumber data primer yang penulis sajikan diperoleh dari data angket, hasil wawancara dan observasi (field research) serta data sekunder yang diperoleh dari hasil penelitian kepustakaan (library research), dengan mempelajari peraturan-peraturan dan buku-buku yang berkaitan dengan penelitian ini. Spesifikasi penelitian dalam penulisan ini bersifat deskriptif analitis. Teori yang digunakan oleh penulis dalam penelitian ini adalah Teori Efektivitas Hukum yang termasuk di dalam Teori Yuridis Sosiologis. Dari hasil penelitian ini menunjukkan bahwa dalam memberikan perlindungan hukum terhadap hak-hak ABK, PT Samudera Indonesia telah memenuhi ketentuan-ketentuan peraturan perundang-undangan Nasional dan Internasional, yaitu Undang-Undang No. 15 Tahun 2016 yang merupakan pengesahan sekaligus ratifikasi terhadap pemberlakuan Maritime Labour Convention (MLC) 2006, sebagai Undang-Undang Perburuhan Maritim di Indonesia.
\end{abstract}

Kata kunci : Anak Buah Kapal (ABK), Implementasi, Perlindungan Hukum.

\begin{abstract}
Crew members are all people who work on the ship, who are in charge of operating and maintaining the ship and its cargo, other than the captain or ship leader. In carrying out their duties they often experience difficulties ranging from fraudulent job vacancies, violence, wages that are still below the minimum wage, to crimes of robbery and persecution. This study aims to discuss the implementation of Law No. 15. Year 2016 in protecting the rights of Ship Crew, in a case study research at PT Samudera Indonesia, Semarang branch. This research is based on empirical juridical research based on normative law science or statutory regulations. The primary data source that the writer presents is obtained from questionnaire data, the results of interviews and observations (field research) and secondary data obtained from the results of library research, by studying the rules and books related to this research. The research specification in this writing is descriptive analytical. The theory used by the author in this study is the Theory of Legal Effectiveness which is included in the Sociological Juridical Theory. The results of this study indicate that in providing legal protection to the rights of crew members, PT Samudera Indonesia has fulfilled the provisions of National and International legislation, namely Law No. 15 of 2016 which is both the ratification and the ratification of the 2006 Maritime Labor Convention (MLC), as the Maritime Labor Law in Indonesia.
\end{abstract}

Keywords : Ship Crew, Implementation, Legal Protection. 


\section{Pendahuluan}

Kapal sebagai sarana transportasi di laut, tentunya harus disiapkan secara laik dan baik, serta diawaki dengan ABK yang memiliki keterampilan yang cakap, handal dan kompeten dibidangnya. Organisasi dunia tentang kemaritiman yaitu IMO (International Maritime Organization), sangat peduli terhadap ABK yang bekerja di kapal. IMO berusaha untuk memberikan perlindungan terhadap hak-hak para ABK yang bekerja di kapal. Salah satunya melakukan kerjasama dengan organisasi perburuhan internasional atau International Labour Organization (ILO) dan mengeluarkan satu konvensi tentang perburuhan maritim yang dikenal dengan Maritime Labour Convention (MLC) 2006 [1].

Pada Kamis, 8 September 2016, Pemerintah Indonesia meratifikasi MLC 2006, yang bertujuan memperkuat perlindungan terhadap hak-hak para pelaut dan ABK Indonesia. Kemudian di undangkan pada tanggal 6 Oktober 2016, dengan Undang-Undang Nomor 15 Tahun 2016 tentang Pengesahan MLC 2006 sebagai Undang-Undang Perburuhan Maritim di Indonesia, tercatat dalam lembaran Negara Republik Indonesia Tahun 2016 Nomor 193 [2]. Menteri Ketenagakerjaan, Hanif Dhakiri mengatakan bahwa, ratifikasi MLC 2006, selain memberikan perlindungan tenaga kerja di sektor maritim (pelaut), konvensi ini juga memberikan perhatian terhadap persaingan yang adil bagi para pemilik kapal (ship owner) dalam industri perkapalan dunia.

Berdasarkan Pasal 18 ayat (3) PP No. 7 Tahun 2000 tentang Kepelautan, yang mengatur mengenai hak-hak dan kewajiban ABK, Pemerintah Indonesia selalu menunjukkan komitmennya dalam melindungi hak-hak dan kesejahteraan ABK Indonesia. Namun demikian, masih saja ada ABK Indonesia yang masih diperlakukan dan mendapatkan gaji, di bawah standar yang diberikan oleh International Transport Workers Federation (ITF), pada saat mereka bekerja di kapal pelayaran Internasional. Bahkan jaminan kesehatan, keselamatan, keamanan, terkadang masing kurang diperhatikan. Beberapa juga mengalami aksi kekerasan, penipuan, percaloan, pungli di perairan, dan mafia penyelundup serta perampokan dan penyanderaan. Pemerintah Indonesia melalui Kementerian Luar Negeri mengatakan siap menangani masalah tersebut secara serius. Dari data Kementerian Luar Negeri, banyak ABK Indonesia yang tersandung persoalan hukum di luar negeri. Tahun 2014 ada 606 kasus WNI ABK di luar negeri, 242 sudah selesai tapi ada yang masih proses carry over. Sementara pada 2015, ada 187 kasus baru. Kemudian mengenai kasus penyanderaan yang dialami oleh ABK Kapal MV Sinar Kudus, kapal milik PT Samudra Indonesia, beserta 20 orang ABK, yang dibajak Perompak Somalia pada tanggal 16 Maret 2011. Kapal berbobot 8.911 ton itu membawa Feronikel dengan tujuan Belanda. Ketika dibajak, MV Sinar Kudus berada di Perairan Somalia tepatnya di sekitar 350 mil laut bagian tenggara Oman.

Beberapa fakta yang diungkapkan ini, menjadi wajah buruk dari implementasi UndangUndang Nomor 13 Tahun 2003 tentang Ketenagakerjaan [3], Undang-Undang Nomor 39 Tahun 2004 tentang Penempatan dan Perlindungan Tenaga Kerja Indonesia di Luar Negeri dan Undang-Undang No. 17 Tahun 2008 tentang Pelayaran, beserta peraturan pelaksanaannya. Untuk menyempurnakan peraturan tersebut, maka Pemerintah Indonesia mengeluarkan Undang-Undang No. 15 Tahun 2016. Dalam pelaksanaannya, peraturan ini tentu belum sepenuhnya dapat tercapai. Untuk itu penulis tertarik untuk melakukan penelitian mengenai $A B K$ kapal Indonesia yang bekerja di kapal milik perusahaan dalam negeri, dengan rute pelayaran nasional dan internasional, di salah satu perusahaan Indonesia, yaitu PT Samudera Indonesia.

Permasalahan yang penulis rumuskan adalah mengenai bagaimana implementasi UU No. 15 Tahun 2016 ini, telah dapat memberikan perlindungan terhadap hak-hak Anak Buah Kapal di PT Samudera Indonesia. Dalam Review Studi Terdahulu telah dibahas oleh Thio Haikal Anugerah mengenai Pengaturan Tentang Pelaut Dalam Maritime Labour Convention 2006 dan Implementasinya di Indonesia dengan pokok bahasan mengenai bagaimana pengaturan tentang Pelaut dalam Maritime Labour Convention 2006 dan implementasi Maritime Labour Convention 2006 di Indonesia The adoption of the MLC by the ILO was carried out with the aim of protecting seafarers and the shipping industry. [4].

Mengingat luasnya masalah yang dapat dibahas dari judul penelitian ini, maka peneliti hanya akan meneliti dan menuangkan hasil 
penelitian dalam pembahasan tentang "Implementasi Undang-Undang Nomor 15 Tahun 2016 Dalam Melindungi Hak-Hak Anak Buah Kapal di PT. Samudera Indonesia". Penelitian dilakukan di kapal-kapal milik PT. Samudera Indonesia, yang pengoperasian kapalkapalnya di perairan dalam negeri Indonesia dan juga pelayaran luar negeri, yang masuk dan sandar di pelabuhan Semarang dan diageni oleh PT. Samudera Indonesia cabang Semarang.

\section{Materi dan Metode}

Penelitian ini bertujuan untuk mengetahui implementasi atau pemberlakuan dan upaya yang perlu dilakukan untuk memenuhi ketentuan UU No. 15 Tahun 2016 dalam melindungi hak-hak Anak Buah Kapal di PT Samudera Indonesia.

Metode yang digunakan penulis dalam penelitian ini adalah pendekatan penelitian hukum yuridis empiris, yang berbasis pada ilmu hukum normatif dengan mengamati bagaimana reaksi dan interaksi yang terjadi ketika sistem norma itu bekerja di dalam masyarakat [5].

Teori adalah kumpulan dari konsep, prinsip, definisi, proposisi yang terintegrasi, yang menyajikan pandangan sistematis tentang suatu fenomena dengan fokus hubungan antar variabel untuk menjelaskan suatu fenomena [6]. Teori yang digunakan oleh penulis dalam penelitian ini adalah Teori Efektivitas Hukum, yang termasuk di dalam Teori Yuridis Sosiologis.

Data primer diperoleh dengan melakukan studi lapangan (field research) dengan cara angket, wawancara dan observasi [7]. Data angket disajikan dalam bentuk tabel, dan dalam kalimat deskriptif didasarkan dari data perhitungan statistik, disajikan dengan kalimat yang bersifat deskriptif dan berupa narasi yang mudah dipahami [5]. Sedangkan metode wawancara menurut Moh. Yamin, ada tiga, yaitu wawancara bebas, wawancara terpimpin, dan wawancara bebas terpimpin [8]. Jenis wawancara yang dipilih dalam penelitian ini adalah wawancara bebas terpimpin, yang dilakukan dengan responden non random sampling. Data sekunder adalah data yang diperoleh melalui bahan kepustakaan. Pengumpulan data ini dilakukan dengan studi kepustakaan.

Proses pengolahan data yang dilakukan adalah dengan memeriksa, meneliti data yang diperoleh untuk menjamin apakah data dapat dipertanggungjawabkan sesuai dengan kenyataan, melalui proses perhitungan rumus statistik dan editing. Analisis data yang digunakan adalah analisis data kuantitatif yaitu analisa pengolahan data primer berupa angka-angka menggunakan rumus statistik dari program aplikasi IBM SPSS Statistics version 21. Sedangkan data primer wawancara dan observasi serta data sekunder dianalisis mengunakan analisis data kualitatif.

\section{Hasil dan Pembahasan}

Salah satu kegiatan dalam pengumpulan data adalah mengadakan pengukuran. Pengukuran senantiasa dipakai dalam setiap metode, baik metode observasi, angket, wawancara, test, eksperimen, maupun metode pengumpulan data lainnya [9]. Pengukuran data dalam penelitian yang penulis lakukan bertempat di kapal-kapal milik dan di Perusahaan Pelayaran Nasional PT Samudera Indonesia, Tbk Semarang, yang beralamatkan di Jl. Perkutut No.2 Kota Lama Semarang, pada bulan Juli sampai dengan Agustus 2019.

Selama rentang waktu penelitian yang penulis lakukan, ada dua buah kapal milik PT Samudera Indonesia yang memasuki dan sandar di pelabuhan Semarang untuk kegiatan bongkar muat, yaitu kapal MT Sinar Labuan pada tanggal 11 Juli 2019 dan MT Sinar Johor pada tanggal 13 Agustus 2019. Tipe dari kedua kapal tersebut adalah kapal Oill Chemical Tanker. Kedua kapal tersebut menjadi obyek utama dalam memperoleh data dan informasi. Pengambilan sampel yang penulis lakukan adalah $100 \%$ dari jumlah populasi sebagai sumber data, yaitu 15 orang kru MT Sinar Labuan dan 18 orang kru MT Sinar Johor termasuk Nakhoda. Sehingga keseluruhan sampel adalah 33 orang ABK termasuk Nakhoda. Data dari variabel bebas yang diperoleh dari ke 33 responden menunjukkan bahwa keseluruhan responden adalah laki-laki dengan rentang usia antara 23 sampai dengan 62 tahun. Mengenai tingkat pendidikan responden adalah $3 \%$ dari lulusan SLTP, 52\% dari lulusan SLTA, 21\% lulusan Diploma III yaitu para perwira tingkat operasional, dan 24\% lulusan Sarjana untuk para perwira tingkat manajemen dan Nakhoda kapal.

Dari ke 33 responden, rata-rata memiliki masa kerja 9 bulan sampai dengan 12 bulan. Masa kontrak kerja yang tertuang dalam Perjanjian Kerja Laut adalah maksimal 12 bulan atau 1 tahun, namun perusahaan memberikan satu kali masa tambahan kontrak kerja yang 
dapat diperpanjang satu kali, apabila pelaut dalam kondisi sehat dan siap untuk lanjut bekerja setelah masa kontaknya berakhir. Tetapi ketentuan ini tidak dapat diperpanjang untuk masa kontrak kedua.

PT Samudera Indonesia, sebagai perusahaan pemilik kapal dan sekaligus operator kapal, selalu mengedepankan regulasi dan peraturan dalam setiap kegiatan dan kebijakan yang ditetapkan oleh perusahaan. PT Samudera Indonesia, juga terus meningkatkan pemenuhan terhadap standar persyaratan yang ada dalam regulasi dan kode MLC 2006. Menurut Caturyanto Cahya S, selaku Branch Manager PT Samudera Indonesia, Tbk cabang Semarang, menyatakan bahwa PT Samudera Indonesia selalu mengikuti, mentaati dan melaksanakan ketentuan peraturan dan kebijakan yang ditetapkan oleh pemerintah, termasuk ketentuan UU No. 15 Tahun 2016.

Implementasi UU No. 15 Tahun 2016 ini, dapat dilihat dari hasil penelitian yang penulis sajikan sebagai berikut.

\section{Persyaratan Minimum bagi ABK untuk Bekerja di Kapal.}

Klausul tentang persyaratan minimum yang harus dipenuhi oleh ABK untuk bekerja di kapal, sesuai yang tercantum dalam ketentuan MLC 2006, meliputi batas usia minimum (regulasi/ kode 1.1); sertifikat kesehatan (regulasi/ kode 1.2); pelatihan dan kualifikasi (regulasi/ kode 1.3); dan sistem perekrutan dan penempatan di kapal (regulasi/kode 1.4) [10]. Hal ini ditegaskan kembali dalam Pasal 17 PP No. 7 Tahun 2000 tentang Kepelautan, yang menjelaskan bahwa, untuk dapat bekerja di kapal maka sebagai awak kapal, wajib memenuhi persyaratan seperti sertifikat keahlian pelaut dan/ atau sertifikat keterampilan pelaut; berumur sekurang-kurangnya 18 tahun; sehat jasmani dan rohani berdasarkan hasil pemeriksaan kesehatan yang khusus dilakukan untuk itu; dan di sijil. Penetapan batas usia minimum untuk dapat bekerja di kapal sesuai dengan regulasi/ kode 1.1 MLC 2006 adalah mereka yang telah berusia di atas 18 tahun. Ini juga sesuai dengan ketentuan dalam Pasal 1 ayat (26) dari UU No. 13 Tahun 2003 tentang Ketenagakerjaan mengenai pembatasan usia di bawah 18 tahun adalah usia anak-anak.
Dari data yang diperoleh mengenai usia responden secara keseluruhan $\mathrm{ABK}$ yang bekerja di kapal milik PT Samudera Indonesia telah memenuhi ketentuan dari Pasal 68 UU No. 13 Tahun 2003 yaitu berusia diatas 18 tahun. PT Samudera Indonesia, sebelum menerima para pelaut untuk dipekerjakan di kapal-kapal miliknya terlebih dahulu dilakukan seleksi administrasi diantaranya adalah mengenai kondisi usianya melalui kartu identitas diri atau pasport.

Didasarkan pada regulasi/kode 1.2 MLC 2006, maka setiap ABK yang akan bekerja di kapal diharuskan untuk melakukan perekaman medis (medical check up). Pernyataan sehat tersebut di tunjukkan dengan sertifikat kesehatan (medical certificate). Menurut Wasono Hadi selaku Manager Operasional PT Samudera Indonesia Cabang Semarang, ABK tidak cukup hanya memiliki sertifikat kesehatan saja, tetapi juga dilakukan pemeriksaan secara periodik setiap setahun sekali dengan pemeriksaan bebas narkotika dan obat-obatan terlarang serta HIV.

Dari hasil analisis statistik data mengenai kepemilikan sertifikat kesehatan oleh para ABK kapal MT Sinar Labuan dan MT Sinar Johor menunjukkan bahwa para ABK di kapal telah memiliki sertifikat kesehatan. Hal ini sejalan dengan ketentuan Pasal 86 dan 87 UU No. 13 Tahun 2003 tentang Ketenagakerjaan.

Ketentuan dalam regulasi/ kode 1.3 MLC 2006 bertujuan menjamin dan memastikan bahwa setiap ABK yang akan bekerja di kapal, sebelumnya telah menerima suatu pelatihan atau familiarisasi yang dibutuhkan sesuai dengan tugas dan tanggung jawabnya nanti di kapal, seperti cara penggunaan peralatan keselamatan, alat pelindung diri, sistem manajemen keselamatan dan keamanan di kapal. Data yang diperoleh menunjukkan bahwa seluruh responden menyetujui perlunya pelatihan dan kualifikasi dalam perekrutan, untuk meningkatkan kualifikasi ABK yang akan bekerja di kapal. Hasil data ini telah sesuai juga dengan Pasal 12 UU No. 13 Tahun 2003 tentang Ketenagakerjaan. Dalam perekrutan dan penempatan ABK di kapal sesuai Regulasi/ Kode 1.4 MLC 2006, setiap ABK atau pelaut berhak untuk diterima dan bekerja di kapal. 
Perusahaan haruslah menyediakan fasilitas pelayanan perekrutan yang mudah dan efisien serta didasarkan pada regulasi perekrutan pelaut dan penempatannya [12].

Dalam ketentuan BAB VI Pasal 31 sampai dengan Pasal 38 dari UU No. 13 Tahun 2003 tentang Ketenagakerjaan, secara umum menjelaskan mengenai ketentuan perekrutan dan penempatan kerja bagi para tenaga kerja. Pasal 20 PP No. 7 Tahun 2000 tentang Kepelautan, menjelaskan mengenai kesempatan kerja di kapal, fasilitas dan kemampuan pelaut yang penempatannya didasarkan pada kompetensinya. PT Samudera Indonesia, secara keseluruhan dalam proses perekrutan dan penempatannya ABK di kapal, telah memberikan suatu sarana dan akses yang mudah kepada para calon $\mathrm{ABK}$, untuk mengirimkan $\mathrm{CV}$ ataupun lamaran pekerjaan melalui website perusahaan, yaitu di www.samudera.id. Para calon $\mathrm{ABK}$ juga dapat secara langsung mengirimkan $\mathrm{CV}$ melalui email: talent.recruitment@samudera.id, tanpa harus datang langsung ke Perusahaan. Dalam proses perekrutan setelah ada pemanggilan, para calon ABK akan mengikuti serangkaian proses perekrutan, diantaranya dengan melaksanakan test dan uji kompetensi bagi calon ABK.

Dari hasil data penelitian, wawancara dan observasi di lapangan baik di perusahaan atau di kedua kapal milik PT Samudera Indonesia, telah menerapkan dan mengimplementasikan persyaratan minimum bagi $\mathrm{ABK}$ untuk dapat bekerja di kapal. Jika dilihat dari sisi perlindungan hukumnya, maka telah memenuhi standar kriteria yang ditetapkan di dalam UU No. 15 Tahun 2016.

\section{Kondisi Lingkungan Kerja di Kapal}

Ketentuan dalam Regulasi 2 tentang kondisi lingkungan kerja, meliputi, perjanjian kerja laut (regulasi/ kode 2.1); gaji atau upah kerja (regulasi/ kode 2.2); jam kerja dan jam istirahat (regulasi/ kode 2.3); cuti (regulasi/ kode 2.4); dan Pemulangan selesai kontrak kerja (regulasi/ kode 2.5). Kondisi lingkungan kerja di kapal merupakan penggambaran dari kesejahteraan bagi ABK yang bekerja di kapal tersebut. Di dalam Pasal 151 ayat (1), UU No. 17 Tahun 2008 tentang Pelayaran, menjelaskan mengenai kesejahteraan awak kapal dan kesehatan penumpang. Dalam
Pasal 21 sampai dengan Pasal 26 PP No.7 Tahun 2000 tentang Kepelautan, pada Bagian Keempat, juga menjelaskan secara rinci mengenai Kesejahteraan Awak Kapal.

Dasar hukum dibuatnya Perjanjian Kerja Laut (PKL), pada prinsipnya mengacu pada Buku II Bab 4 KUHD tentang Perjanjian Kerja Laut (PKL), khususnya Bagian Pertama tentang Perjanjian Kerja Laut pada umumnya. Ketentuan PKL dalam KUHD tersebut juga mengatur hal-hal bersifat khusus, misalnya, isi (substansi) PKL yang lebih luas dan pembuatan PKL harus di hadapan Syahbandar (Pasal 400 dan Pasal 401 KUHD jo Pasal 18 PP No. 7 Tahun 2000). Walaupun demikian, beberapa ketentuan PKL dalam KUHD tersebut, merujuk lebih lanjut pada ketentuan perjanjian-perjanjian melakukan pekerjaan (Bab Ketujuh A - Buku II) KUH Perdata, seperti misalnya disebut dalam Pasal 396 KUHD.

Perjanjian kerja ini juga menjadi ketentuan pokok di dalam Bab IX UU No. 13 Tahun 2003 tentang Ketenagakerjaan. Dan juga di tegaskan dalam UU No. 17 Tahun 2008 tentang Pelayaran pada Pasal 151 ayat (2), dimana ketentuan dan kesepakatan dalam pemenuhan kesejahteraan kerja bagi awak kapal harus dinyatakan dalam bentuk suatu perjanjian kerja yang dinamakan PKL antara awak kapal dengan pemilik atau operator kapal sesuai dengan peraturan perundangundangan.

Tabel 1. Statistik data Perjanjian Kerja Laut

\begin{tabular}{|c|c|c|c|c|c|c|c|c|}
\hline & & B1 & B2 & B3 & B4 & B5 & B6 & B7 \\
\hline & Valid & 33 & 33 & 33 & 33 & 33 & 33 & 33 \\
\hline \multirow[t]{2}{*}{$\mathrm{N}$} & Missin & 0 & 0 & 0 & 0 & 0 & 0 & 0 \\
\hline & Mean & & & & 161 & 461 & 155 & 4.52 \\
\hline \multicolumn{2}{|c|}{$\begin{array}{l}\text { Std. Er } \\
\text { Mean }\end{array}$} & .068 & .097 & .087 & .086 & .086 & .098 & .098 \\
\hline \multicolumn{2}{|c|}{ Median } & 5.00 & 5.00 & 5.00 & 5.00 & 5.00 & 5.00 & 5.00 \\
\hline \multicolumn{2}{|c|}{ Range } & 1 & 2 & 1 & 1 & 1 & 2 & 2 \\
\hline \multicolumn{2}{|c|}{ Minimum } & 4 & 3 & 4 & 4 & 4 & 3 & 3 \\
\hline \multicolumn{2}{|c|}{ Maximum } & 5 & 5 & 5 & 5 & 5 & 5 & 3 \\
\hline
\end{tabular}

Dari data tabel 1 menunjukkan bahwa seluruh ABK menyatakan telah memiliki dokumen atau surat Perjanjian Kerja Laut yang masih valid, dan isi dari Perjanjian Kerja Laut tersebut telah sesuai dengan ketentuan yang ada dalam peraturan yang diberlakukan. Setelah ABK menyelesaikan jangka waktu kontrak kerja, maka para $\mathrm{ABK}$ akan dipulangkan menuju ke kota asal dengan fasilitas dan biaya dari Perusahaan. 
Dalam ketentuan Pasal 22 (a) PP No. 7 Tahun 2000 tentang Kepelautan, menjelaskan mengenai upah minimum bagi awak kapal. Berdasarkan ketentuan peraturan tersebut, maka Kementrian Perhubungan melalui Direktorat Jenderal Perhubungan Laut, menetapkan bahwa kebijakan pengupahan bagi para pelaut atau ABK didasarkan pada ketentuan dalam undang-undang ketenagakerjaan, pada bagian Kedua mulai Pasal 88 sampai dengan Pasal 98 UU No. 13 Tahun 2003 tentang Pengupahan.

PT Samudera Indonesia selalu mengutamakan dalam pemenuhan atas gaji para $A B K$ lengkap dengan tunjangan dan membayarkannya rutin setiap bulan. PT Samudera Indonesia telah memberikan atas hak upah atau gaji kepada seluruh ABK sesuai dengan ketentuan perundang-undangan yang diberlakukan oleh pemerintah. Regulasi/ kode 2.3 MLC 2006 memastikan bahwa setiap ABK berhak mendapatkan jam istirahat yang sesuai dan cukup. Dimana batas waktu kerja maksimal dalam satu hari tidak boleh melampaui 14 jam, dan tidak boleh lebih dari 72 jam dalam satu minggu. Sedangkan waktu istirahat bagi ABK tidak boleh kurang dari 10 jam dalam satu hari, dan tidak boleh kurang dari 77 jam dalam satu minggu. Waktu istirahat dapat dibagi dalam 2 periode istirahat, yang mana salah satunya tidak boleh kurang dari 6 jam [12].

Tabel 2. Statistik data Jam Kerja dan Jam Istirahat di Kapal

\begin{tabular}{llrrrrr}
\hline & & B18 & B19 & B20 & B21 & B22 \\
\hline & Valid & 33 & 33 & 33 & 33 & 33 \\
$\mathrm{~N}$ & Missin & 0 & 0 & 0 & 0 & 0 \\
& $\mathrm{~g}$ & & & & & \\
Mean & 4.39 & 4.55 & 4.61 & 4.42 & 4.45 \\
Std. Error of Mean & .106 & .088 & .086 & .098 & .098 \\
Median & 4.00 & 5.00 & 5.00 & 4.00 & 4.00 \\
\hline
\end{tabular}

Sebelum melaksanakan dinas jaga maka keseluruhan $\mathrm{ABK}$ di kapal telah diberikan waktu istirahat minimal 10 jam sesuai dengan ketentuan. Data pada B18 sampai dengan B22 menunjukkan bahwa ABK merasa nyaman dengan waktu istirahat yang diberikan dan ditetapkan di kapal. Setiap perusahaan juga wajib mempedomani mengenai ketentuan waktu kerja berdasarkan pada Pasal 77 ayat (2) UU No. 13 Tahun 2013 tentang Ketenagakerjaan mengenai pembagian waktu kerja. Ketentuan jam kerja dan jam istirahat ini sebenarnya adalah untuk menjaga agar ABK selalu dalam kondisi yang fit dan bugas untuk bekerja. Karena dikhawatirkan, jika kondisi ABK mengalami kelelahan, maka akan menjadi berbahaya dan berisiko terhadap keselamatan dan keamanan kerja. Regulasi/ kode 2.4 dari konvensi MLC 2006 tentang cuti untuk Anak Buah Kapal, merupakan jaminan dari ILO kepada para ABK untuk mendapatkan hak atas cuti. Dimana dalam ketentuan MLC 2006, setiap ABK berhak mendapatkan cuti dengan perhitungan 2,5 hari dalam setiap kalender bulanan.

Tabel 3. Statistik Data Cuti

\begin{tabular}{llrrrr}
\hline & & B23 & B24 & B25 & B26 \\
\hline $\mathrm{N}$ & Valid & 33 & 33 & 33 & 33 \\
& Missin & 0 & 0 & 0 & 0 \\
Mean & $\mathrm{g}$ & & & & \\
Std. Error of Mean & 4.52 & 4.39 & 4.42 & 4.30 \\
Median & .108 & .123 & .123 & .119 \\
\hline
\end{tabular}

Dari data tabel 3 atas hak cuti bagi ABK yang telah menyelesaikan kontrak kerjanya, menunjukkan bahwa $\mathrm{ABK}$ telah mendapatkan hak atas cuti dan bahkan mendapatkan pembayaran annual leave pay diakhir masa kontaknya. Menurut Jerymianus Gilalo, Chief Engineer MV Sinar Johor, pemberian cuti bagi ABK, perusahaan memberikan waktu antara 20 sampai dengan 30 hari di rumah. Apabila selesai masa cutinya, maka ABK diwajibkan untuk melapor kembali ke bagian personalia, untuk dijadwalkan dan ditempatkan kembali di kapal-kapal milik PT Samudera Indonesia.

MLC 2006 dalam ketentuan regulasi/ kode 2.5 memberikan kepastian mengenai hak pemulangan pelaut ke rumahnya. Beberapa persyaratan dan ketentuan bagi ABK untuk mendapatkan hak untuk pemulangannya ke pelabuhan asal.

Tabel 4. Statistik data Pemulangan

\begin{tabular}{|c|c|c|c|c|c|c|c|}
\hline & & B27 & B28 & B29 & B30 & B31 & B32 \\
\hline \multirow{2}{*}{$\mathrm{N}$} & Valid & 33 & 33 & 33 & 33 & 33 & 33 \\
\hline & Missing & 0 & 0 & 0 & 0 & 0 & 0 \\
\hline \multicolumn{2}{|c|}{ Mean } & 4.45 & 4.33 & 4.42 & 4.48 & 4.27 & 4.48 \\
\hline \multicolumn{2}{|c|}{ Std. Error of Mean } & .098 & .104 & .098 & .098 & . 109 & .108 \\
\hline \multicolumn{2}{|c|}{ Median } & 4.00 & 4.00 & 4.00 & 5.00 & 4.00 & 5.00 \\
\hline
\end{tabular}

Tabel 4 memberikan gambaran yang pasti bahwa secara keseluruhan, ABK yang sudah habis masa kontrak kerjanya, dalam proses pemulangannya semua beban biaya dan akomodasi di tanggung sepenuhnya oleh pihak perusahaan. Lamanya waktu yang diberikan perusahaan kepada ABK yang sedang cuti atau istirahat di rumah adalah 20 hari sampai dengan 30 hari. 


\section{Akomodasi, Fasilitas Rekreasi, Makanan dan Pelayanan Katering}

Regulasi/kode 3 dari MLC 2006 ini memberikan jaminan kepada para $\mathrm{ABK}$ dan memastikan bahwa setiap ABK mendapatkan tempat tinggal yang layak di kapal, fasilitas rekreasi atau hiburan, makanan dan minuman sesuai dengan standar gizi yang ditentukan oleh dinas kesehatan, serta pelayanan katering.

Pada saat penulis melakukan observasi di kapal MV. Sinar Labuan dan MV. Sinar Johor, penulis mendapati bahwa akomodasi dan tempat hiburan atau rekreasi di kapal cukup luas dan bagus. Kamar-kamar ABK memiliki luas rata-rata $4 \mathrm{~m}^{2}$ sampai $5 \mathrm{~m}^{2}$ dan dilengkapi dengan lemari pakaian dan meja kerja. Untuk kamar perwira luasnya mencapai $12 \mathrm{~m}^{2}$ sampai dengan $15 \mathrm{~m}^{2}$ dengan fasilitas kamar mandi di dalam dengan fasilitas air hangat, lemari pakaian, lemari dokumen, meja kerja, dan ruang tamu. Dikapal juga difasilitasi ruang rekreasi atau hiburan yaitu mess room dan tempat olah raga. Fasilitasfasilitas dikapal seperti ruang perawatan, tempat ibadah, ruang karaoke dan bersantai telah dipenuhi oleh pihak perusahaan. Kondisi ruangan akomodasi juga telah difasility dengan Air Conditioner (AC) central, yang menjadikan ruangan akomodasi menjadi sangat nyaman dan menyenangkan.

Fasilitas sanitasi dan kamar mandi di kapal juga telah memenuhi standar baik jumlah maupun kelayakan kondisi dari sanitasi tersebut. Ruang akomodasi yang bersih telah mencerminkan bahwa kapalkapal di bawah manajemen PT Samudera Indonesia, telah terbebas dari hama dan insektisida. Ini dibuktikan dengan dimilikinya sertifikat pembebasan tikus dan insektisida (Derating Exemption Certificate).

Dari hasil penelitian, penulis dapat menyimpulkan bahwa PT Samudera Indonesia dalam hal pemberian fasilitas akomodasi dan rekreasi di kapal telah memenuhi ketentuan dari Undang-Undang No. 15 Tahun 2016 dan Pasal 33 Peraturan Pemerintah No. 7 Tahun 2000. Mengenai makanan dan standar pelayanan sesuai (regulasi/ kode 3.2) di PT Samudera Indonesia diberikan kepada Nakhoda dan Koki di kapal untuk mengaturnya.
Tabel 5. Statistik data Makanan dan Pelayanan

\begin{tabular}{|c|c|c|c|c|c|c|c|c|}
\hline & & C17 & $\mathrm{C} 18$ & $\mathrm{C} 19$ & $\mathrm{C} 20$ & $\mathrm{C} 21$ & $\mathrm{C} 22$ & $\mathrm{C} 23$ \\
\hline \multirow{3}{*}{$\mathrm{N}$} & Valid & 33 & 33 & 33 & 33 & 33 & 33 & 33 \\
\hline & Missin & 0 & 0 & 0 & 0 & 0 & 0 & 0 \\
\hline & $\mathrm{g}$ & & & & & & & \\
\hline \multicolumn{2}{|c|}{ Mean } & 4.67 & 4.58 & 4.76 & 4.67 & 4.58 & 4.58 & 4.55 \\
\hline \multicolumn{2}{|c|}{$\begin{array}{l}\text { Std. Error of } \\
\text { Mean }\end{array}$} & .083 & .098 & .076 & .083 & .098 & .087 & .107 \\
\hline \multicolumn{2}{|c|}{ Median } & 5.00 & 5.00 & 5.00 & 5.00 & 5.00 & 5.00 & 5.00 \\
\hline
\end{tabular}

Di kapal MV Sinar Labuan dan MV Sinar Johor, kebijakan mengenai penyediaan makanan dan pelayanan telah sesuai dengan ketentuan yang di tetapkan oleh pihak perusahaan dan peraturan MLC 2006, dimana dalam pengolahan makanan, koki atau juru masak harus dapat menyajikan menu dengan nilai gizi dengan jumlah 3600 kalori perhari yang diperlukan awak kapal. Pemeriksaan terhadap kadaluwarsa bahan makanan, kualitas dan kebersihannya juga selalu dilakukan pada saat pengadaan dan supply bahan makanan telah sesuai ketentuan Pasal 25 dan 34 PP No. 7 Tahun 2000.

\section{Jaminan Kesehatan, Perawatan Medis, Kesejahteraan dan Jaminan Sosial Tenaga Kerja}

Perlindungan terhadap jaminan kesehatan, perawatan medis, kesejahteraan dan jaminan social bagi setiap ABK merupakan kewajiban dari pihak perusahaan. Tanggung jawab (beban) majikan dalam UU No. 33 Tahun 1947 tentang Kecelakaan, dialihkan kepada program jaminan sosial (social security) dengan dibentuknya Asuransi Sosial Tenaga Kerja (Astek) pada 26 Nopember 1977. Kemudian UU No. 33 Tahun 1947 digantikan dengan diterbitkannya UU No. 3 Tahun 1992 tentang Jamsostek dan peraturan pelaksanaannya, PP No. 14 Tahun 1993.

Dalam ketentuan MLC 2006, Regulasi 4, memberikan kepastian terhadap perlindungan hak-hak ABK dalam mendapatkan jaminan kesehatan, perawatan medis, kesejahteraan dan jaminan sosial ketenagakerjaan. Dalam jaminan kesehatan dan perawatan medis sesuai regulasi/ kode 4.1 MLC 2006, juga relevan dengan ketentuan dalam Pasal 86 UU No. 13 Tahun 2003 tentang Ketenagakerjaan. Pasal 28 PP No. 7 Tahun 2000, juga menjelaskan mengenai kewajiban setiap pengusaha kapal dalam menanggung biaya perawatan dan pengobatan bagi awak kapal yang sakit atau cidera selama berada dan bekerja di atas kapal. Selain pengusaha kapal wajib membiayai perawatan dan pengobatan, 
pengusaha juga wajib membayar gaji penuh jika ABK tetap berada atau dirawat di kapal.

Tabel 6. Statistik data Kesehatan dan

\begin{tabular}{|c|c|c|c|c|c|c|}
\hline \multicolumn{7}{|c|}{ Perawatan Medis } \\
\hline & & D1 & D2 & D3 & D4 & D5 \\
\hline \multirow{3}{*}{$\mathrm{N}$} & Valid & 33 & 33 & 33 & 33 & 33 \\
\hline & Missin & 0 & 0 & 0 & 0 & 0 \\
\hline & $\mathrm{g}$ & & & & & \\
\hline \multirow{3}{*}{\multicolumn{2}{|c|}{$\begin{array}{l}\text { Mean } \\
\text { Std. Error of Mean } \\
\text { Median }\end{array}$}} & 4.70 & 4.24 & 4.55 & 4.58 & 4.52 \\
\hline & & .081 & .098 & .088 & .087 & .088 \\
\hline & & 5.00 & 4.00 & 5.00 & 5.00 & 5.00 \\
\hline
\end{tabular}

Dalam tabel 6 diperoleh data bahwa perlindungan atas keselamatan dan penjaminan kesehatan bagi para $\mathrm{ABK}$ di kapal PT Samudera Indonesia, telah dilaksanakan sesuai dengan ketentuan yang ditetapkan oleh pemerintah. Wasono Hadi menjelaskan bahwa ABK yang sakit atau mengalami kecelakaan di kapal pada saat bekerja, seluruh biaya pengobatan dan perawatan baik di kapal atau di Rumah Sakit, menjadi tanggung jawab perusahaan. Demikian juga, karena akibat dari sakit atau kecelakaan tersebut, sehingga menjadikan ABK tidak dapat melaksanakan tugas dan tanggung jawabnya, perusahaan tetap memberikan dan membayarkan gaji pokok dari ABK tersebut sesuai yang tertuang dalam kesepakatan kontrak Perjanjian Kerja Lautnya

Seluruh ABK di PT Samudera Indonesia telah dijamin dengan Asuransi Tenaga Kerja (Astek) dari BPJS dan plafon pertanggungan dari perusahaan. Selain dari pada itu, perusahaan PT Samudera Indonesia juga tergabung dalam Protection and Indemnity Club (P\&I Club) yang merupakan asuransi bersama para pemilik/operator kapal untuk menutupi risiko yang tidak dapat diasuransikan pada perusahaan asuransi [12]. Untuk jaminan kebijakan manajemen perusahaan tentang kesejahteraan sosial ketenagakerjaan sesuai regulasi/ kode 4.5 MLC 2006, relevan dengan bagian ketiga Pasal 99 UU No. 13 Tahun 2003 tentang Ketenagakerjaan.

Tabel 7. Statistik data Kebijakan Manajemen Perusahaan

\begin{tabular}{|c|c|c|c|c|c|c|}
\hline & & D6 & D7 & D8 & D9 & D10 \\
\hline \multirow{3}{*}{$\mathrm{N}$} & Valid & 33 & 33 & 33 & 33 & 33 \\
\hline & Missin & 0 & 0 & 0 & 0 & 0 \\
\hline & Mean & 4.36 & 4.30 & 4.42 & 4.82 & 4.30 \\
\hline \multicolumn{2}{|c|}{ Std. Error of Mean } & .114 & .102 & .098 & .068 & .119 \\
\hline \multicolumn{2}{|c|}{ Median } & 4.00 & 4.00 & 4.00 & 5.00 & 4.00 \\
\hline
\end{tabular}

Tabel 8. Statistik data Jaminan Sosial Ketenagakerjaan

\begin{tabular}{|c|c|c|c|c|c|}
\hline & D11 & D12 & D13 & D14 & D15 \\
\hline \multirow{2}{*}{$\mathrm{N}$} & 33 & 33 & 33 & 33 & 33 \\
\hline & 0 & 0 & 0 & 0 & 0 \\
\hline Mean & & 4.64 & 4.76 & 4.64 & 4.67 \\
\hline Std. Error of Mean & & .085 & .076 & .096 & .083 \\
\hline Median & & 5.00 & 5.00 & 5.00 & 5.00 \\
\hline
\end{tabular}

PT Samudera Indonesia, untuk jaminan kesejahteraan didasarkan pada UU No. 13 Tahun 2003 tentang Ketenagakerjaan dan PP No. 7 Tahun 2000 tentang Kepelautan. Apabila ada ABK yang mengalami kecelakaan kerja bahkan sampai mengalami cidera dan cacat fisik, maka segala biaya kompensasi didasarkan pada peraturan tersebut. ABK akan mendapatkan ganti kerugian atau yang dikenal dengan uang santunan kecelakaan kerja yang besarannya disesuaikan dengan kondisi yang dialami oleh ABK tersebut. Berdasarkan ketentuan MLC 2006 mengenai perlindungan jaminan sosial tenaga kerja yaitu $\mathrm{ABK}$, setidaknya harus menyediakan tiga hal yaitu untuk perawatan medis (medical care), tunjangan sakit (sickness benefit) dan tunjangan kecelakaan kerja (employment injury benefit) [12].

Dari uraian keterangan dan pembahasan di atas, maka dapat ditarik kesimpulan bahwa implementasi Undang-Undang No.15 Tahun 2016 tentang Pengesahan Maritime Labour Convention (MLC) 2006, sebagai UndangUndang Perburuhan Maritim di Indonesia, telah secara penuh diterapkan dan dilaksanakan di kapal-kapal milik PT Samudera Indonesia. Semua ketentuan terhadap perlindungan hukum dan perlindungan hak-hak Anak Buah Kapal telah dipenuhi dan diperhatikan. Hal ini dibuktikan dengan kapal-kapal milik PT Samudera Indonesia yang telah dinyatakan lolos audit dan pemeriksanan dari Flag State Control ataupun Port State Control serta dinyatakan memenuhi ketentuan yang ada dalam MLC 2006, maka diberikan sertifikat pengesahan yaitu Maritime Labour Convention Certificate.

Perusahaan pelayaran PT Samudera Indonesia, sebagai salah satu perusahaan pelayaran yang kapal-kapalnya dioperasikan dengan rute pelayaran Nasional maupun Internasional, telah mentaati segala peraturan yang diberlakukan. Setiap kekurangan dan ketidaksesuaian dari hasil pemeriksaan segera dilakukan perbaikan dan pemenuhan, sehingga 
mendapatkan kepercayaan dari pemerintah, dan pemerintah memberikan Maritime Labour Convention Certificate, untuk kapal-kapalnya.

\section{Kesimpulan}

Berdasarkan uraian pada bab sebelumnya, hasil penelitian dan pembahasan dapat disimpulkan bahwa implementasi UU No. 15 Tahun 2016 tentang Pengesahan Maritime Labour Convention (MLC) 2006, sebagai Undang-Undang Perburuhan Maritim di Indonesia, telah secara penuh diterapkan dan dilaksanakan di kapal-kapal milik PT Samudera Indonesia. Semua ketentuan terhadap perlindungan hukum dan perlindungan hak-hak ABK telah dipenuhi dan diperhatikan. Kapalkapal yang telah dinyatakan lolos audit dan pemeriksanan serta memenuhi ketentuan MLC 2006, telah memiliki Maritime Labour Convention Certificate (MLC Sertifikat).

\section{Ucapan terima kasih}

Dalam menyelesaikan laporan penelitian ini penulis mendapatkan bimbingan dan motivasi dari banyak pihak, dan penulis mengucapkan terima kasih kepada Yayasan Wiyata Dharma atas dukungan finansialnya pada penelitian ini dan LP3M Politeknik Bumi Akpelni dan PT Samudera Indonesia Cabang Semarang yang telah mendukung terselenggaranya penelitian ini. Penulis juga berterima kasih kepada Bapak Caturyanto Cahya S, S.H., selaku Pimpinan PT. Samudera Indonesia Cabang Semarang dan Bapak Wasono Hadi S, Manajer Operasional PT. Samudera Indonesia Semarang yang memberikan data-data dan informasi guna penyusunan laporan penelitian ini.

\section{Daftar Pustaka}

[1] International Maritime Organization (IMO) and International Labour Organization (ILO), Maritime Labour Convention 2006.

[2] Undang-Undang Republik Indonesia Nomor 15 Tahun 2016 tentang pengesahan MLC 2006 sebagai Undang-Undang Maritim di Indonesia.

[3] Undang-Undang Republik Indonesia Nomor 13 Tahun 2003 tentang Ketenagakerjaan.

[4] T. H. Anugerah, "REGULATION CONCERNING SEAFARER ON MARITIME LABOR CONVENTION 2006 Submitted: September 23 , 2019; Reviewed: October 14, 2019; Accepted: Actober 31, 2019 Keywords : Protection,
Privacy , Encryption , International , National . DOI :," Lampung J. Int. Law, vol. 1, no. 2, pp. 71-78, 2019, doi: 10.35891/ml.v9i1.881.4.

[5] Krismiyarsi, "Hand out Metode Penelitian Hukum", UNTAG Semarang, Semarang, 2018.

[6] H. Nana Sudjana, H. Awal Kusumah, "Proposal Penelitian di Perguruan Tinggi", Sinar Baru Algensindo, Bandung, 2000.

[7] J. Supranto, "Metode Penelitian Hukum dan Statistik", PT Rineka Cipta, Jakarta, (2003).

[8] Moh. Yamin, "Pelatihan Peningkatan Kualitas Penelitian Hukum : Metode Penelitian Hukum Normatif dan Empirik serta Aplikasinya", Fakultas Hukum UNS, Surakarta, 2007.

[11]H. Ishaq, "Metode Penelitian Hukum dan Penulisan Skripsi, Tesis, serta Disertasi", Alfabeta, Bandung, 2017.

[12]ITF, A Seafarers' Bill of Rights, The International Transport Workers Federation (ITF), London, 2006. 